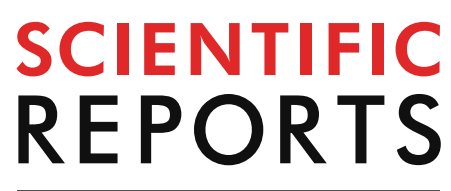

natureresearch

Check for updates

\title{
Leflunomide monotherapy
} versus combination therapy with conventional synthetic disease-modifying antirheumatic drugs for rheumatoid arthritis: a retrospective study

\author{
Daihua Deng ${ }^{1,4}$, Jun Zhou ${ }^{2,4}$, Min $\mathrm{Li}^{1}$, Siyin $\mathrm{Li}^{1}$, Lan Tian ${ }^{1}$, Jinmei Zou ${ }^{1}$, Tingting Wang ${ }^{3}$, \\ Jianhong Wu ${ }^{3}$, Fanxin Zeng ${ }^{2 \bowtie}$ \& Jing Yang ${ }^{1 凶}$
}

Leflunomide (LEF) is a conventional synthetic disease-modifying antirheumatic drugs (csDMARDs) for the treatment of rheumatoid arthritis. However, there are few reports on the comparison of efficacy between LEF alone and combined with other csDMARDs. Here, the efficacy and safety of LEF monotherapy (88) and combination (361) therapy groups were evaluated. After 3 months, there were no significant differences in 28-joint disease activity score (DAS28), health assessment questionnaire (HAQ), erythrocyte sedimentation rate (ESR) and C-reactive protein (CRP) between the monotherapy and combination groups (all $P>0.05$ ). According to the European League Against Rheumatism (EULAR) response criteria, it was found that the DAS28 response rates were similar in the two groups $(P>0.05)$. Besides, the two groups presented similar safety profiles. Subgroup analysis found that there was no difference in efficacy among the three combined therapies (LEF + methotrexate (MTX), LEF + hydroxychloroquine (HCQ), and LEF + MTX + HCQ) and LEF monotherapy. Furthermore, when the dose of LEF was less than $40 \mathrm{mg} /$ day, no significant difference in efficacy was observed between low and high doses. Overall, these results indicated that low dose LEF monotherapy was not inferior to the combination therapy.

Rheumatoid arthritis (RA) is a chronic inflammatory autoimmune disease characterized by synovitis, and its primary clinical manifestations is symmetric arthritis affecting multiple joints. Inflammation and joint erosion cause physical function disorder, which severely reduces the quality of life. The global prevalence of RA is $0.5-1 \%^{1,2}$, the incidence of RA among females is 2 to 3 times than of males, and the incidence in females shows an increasing trend ${ }^{3,4}$. Although multiple studies have reported that the occurrence of RA is related to environmental, hormonal and genetic factors ${ }^{5-7}$, the specific pathogenesis of RA remains unclear, which is difficult to achieve radical cure. The main goal of treating RA at present is to control and alleviate the disease.

Currently, drugs for treating RA mainly include conventional synthetic disease-modifying antirheumatic drugs (csDMARDs), targeted synthetic DMARDs (tsDMARDs), biological DMARDs (bDMARDs), biosimilar DMARDs (bsDMARDs), and glucocorticoids $(\mathrm{GCs})^{8}$. Economical and effective csDMARDs are the first treatment strategy recommended by the European League Against Rheumatism (EULAR) ${ }^{8}$, including leflunomide (LEF), methotrexate (MTX), hydroxychloroquine (HCQ), sulfasalazine (SSZ), cyclosporine, azathioprine and gold salts. Among them, LEF was approved by the Food and Drug Administration for the treatment of RA in 1998 and plays a role in controlling and relieving the condition of the disease through acting on dihydroorotate

${ }^{1}$ Department of Rheumatology, Mianyang Central Hospital, Mianyang, Sichuan, China. ${ }^{2}$ Department of Clinical Research Center, Dazhou Central Hospital, No. 56 Nanyuemiao Street, Tongchuan District, Dazhou, Sichuan, China. ${ }^{3}$ Department of Rheumatology, Dazhou Central Hospital, Dazhou, Sichuan, China. ${ }^{4}$ These authors contributed equally: Daihua Deng and Jun Zhou. ${ }^{\varpi}$ email: zengfx@pku.edu.cn; yangjing6525@163.com 


\begin{tabular}{|c|c|c|c|}
\hline Characteristic & Monotherapy group $(\mathbf{n}=\mathbf{8 8})$ & Combination group $(n=361)$ & $P$-value \\
\hline Age, years (mean, SD) & $52.15(13.35)$ & $50.02(10.52)$ & 0.140 \\
\hline Female (n, \%) & $65(73.86 \%)$ & $294(81.44 \%)$ & 0.077 \\
\hline Male (n, \%) & $23(26.14 \%)$ & $67(18.56 \%)$ & 0.077 \\
\hline Disease duration, months (mean, range) & $95.22(4.13-599.83)$ & $73.48(3.10-450.80)$ & 0.134 \\
\hline \multicolumn{4}{|l|}{ LEF dose/day } \\
\hline$<20$ mg/day $(\mathrm{n}, \%)$ & $39(44.32 \%)$ & $200(55.40 \%)$ & 0.074 \\
\hline$\geq 20$ mg/day (n, \%) & $49(55.68 \%)$ & $161(44.60 \%)$ & 0.074 \\
\hline \multicolumn{4}{|l|}{ Therapeutic regimen } \\
\hline $\operatorname{LEF}(\mathrm{n})$ & 88 & 0 & \\
\hline $\mathrm{LEF}+\operatorname{MTX}(\mathrm{n})$ & 0 & 125 & \\
\hline $\mathrm{LEF}+\mathrm{HCQ}(\mathrm{n})$ & 0 & 88 & \\
\hline $\mathrm{LEF}+\mathrm{MTX}+\mathrm{HCQ}(\mathrm{n})$ & 0 & 148 & \\
\hline
\end{tabular}

Table 1. Baseline demographics and clinical characteristics of the study cohort. LEF leflunomide, MTX methotrexate, HCQ hydroxychloroquine.

dehydrogenase and tyrosine kinase to inhibits pyrimidine synthesis ${ }^{9,10}$. The double-blind randomized trial in RA patients has also found that LEF significantly improves clinical outcomes ${ }^{11,12}$. The recommended dose of LEF is $20 \mathrm{mg} /$ day without loading dose ${ }^{13}$, but studies have shown that the effects of $10 \mathrm{mg} /$ day and $25 \mathrm{mg} / \mathrm{day}$ are similar at week 4, and the incidence of adverse events is positively correlated with the dose of LEF ${ }^{14}$. Elevated liver enzymes, diarrhoea, respiratory infections, nausea, skin rash, dyspepsia, headache and alopecia are common adverse caused by $\mathrm{LEF}^{15,16}$. Some studies have demonstrated that LEF and MTX have similar effects ${ }^{15,17,18}$. However, the results of a randomized, controlled, single-blind study also suggest that LEF is more effective than $\mathrm{MTX}^{19}$. And LEF has a lower incidence of adverse events than MTX ${ }^{19-21}$.

LEF is often used in combination with other drugs in clinic for the treatment of $\mathrm{RA}^{22,23}$. But it has been a hot topic of debate as to whether monotherapy and combination therapy has more advantageous therapeutic effects. Previous studies have shown that combination csDMARDs therapy is better than csDMARD monotherapy ${ }^{22,24-27}$, while other studies have reached inconsistent conclusions, and the results have shown that the efficacy of combination csDMARDs therapy is similar to that of the csDMARD monotherapy ${ }^{28-31}$. At present, most studies on csDMARDs mainly focus on the efficacy and toxicity evaluation of MTX monotherapy and/or in combination with other csDMARDs, while few studies report the efficacy of LEF monotherapy or combination.

Therefore, we conducted a retrospective cohort study of patients treated with LEF and objectively evaluated the efficacy and safety of LEF monotherapy and LEF combined with other csDMARDs (MTX and HCQ). And, a stratified analysis was performed to compare the efficacy of different LEF doses therapy.

\section{Results}

Study population and patient disposition. A total of 449 patients with RA were enrolled in the final analysis, of which 88 were included in the monotherapy group and remaining 361 were included in the combination group. Clinical features of the two groups were similar at baseline (Table 1). In the monotherapy group, 65 patients $(73.86 \%)$ were female; mean age, 52.15 years; and disease duration was 95.22 months. In the combination group, 294 patients (81.44\%) were female; mean age, 50.02 years; and disease duration was 73.48 months. Patients who were administered LEF doses of less than $20 \mathrm{mg}$ accounted for $44.32 \%$ in the monotherapy group and $55.40 \%$ in the combination group. Furthermore, in the combination group, there were 125 patients who were given LEF + MTX, 88 who were given LEF + HCQ, and 148 who were given LEF + MTX + HCQ.

Efficacy. After 3 months of follow-up, primary and secondary endpoints in the monotherapy and combination groups were assessed at baseline, month 1 and month 3 (Table 2, Fig. 1). At baseline, the 28-joint disease activity score (DAS28) in the two groups were $3.13 \pm 1.21$ and $3.19 \pm 1.28$, respectively, with no significant difference $(P>0.05)$. At month 1, DAS28 was significantly decreased in both groups (monotherapy group: $2.65 \pm 0.98$, compared with baseline $P=0.0216$; combination group: $2.70 \pm 1.07$, compared with baseline $P<0.001$ ). At month 3 , DAS28 continued to improve (monotherapy group: $2.36 \pm 0.96$, compared with baseline $P=0.0109$; combination group: $2.37 \pm 0.88$, compared with baseline $P<0.001$ ). However, there was no statistical difference in DAS28 between the two groups at month 1 and month $3(P>0.05)$.

Health assessment questionnaire (HAQ), erythrocyte sedimentation rate (ESR), tender joint count of 28 joints (TJC28), morning stiffness duration (MSD), and patient global assessment (PtGA) had similar results between two groups at baseline, month 1 and month 3 (all $P>0.05$ ), except for swollen joint count of 28 joints (SJC28) at baseline $(P=0.031)$ and C-reactive protein (CRP) at month $1(P=0.021)$ (Table 2, Fig. 1). Compared with baseline, HAQ, ESR, MSD, and PtGA trend toward decreasing in the monotherapy group at month 3 , but there was no statistical significance $(P>0.05)$. In the combination group, HAQ, ESR, MSD, and PtGA decreased significantly at month 3 compared with baseline $(P<0.05)$.

DAS28 response rate was observed in the monotherapy group and the combination group at month 1 and month 3 (Fig. 2). At month 1, 23.53\% of patients in the monotherapy group had a good response, $17.65 \%$ had a moderate response and $58.82 \%$ had no response according to EULAR criteria. The combination group showed 


\begin{tabular}{|c|c|c|c|c|c|c|c|c|c|}
\hline \multirow[b]{2}{*}{ Characteristic } & \multicolumn{3}{|l|}{ Baseline } & \multicolumn{3}{|l|}{ Month 1} & \multicolumn{3}{|l|}{ Month 3} \\
\hline & $\begin{array}{l}\text { Monotherapy group } \\
(\mathbf{n}=\mathbf{8 8})\end{array}$ & $\begin{array}{l}\text { Combination group } \\
(\mathrm{n}=361)\end{array}$ & $P$-value & $\begin{array}{l}\text { Monotherapy group } \\
(\mathrm{n}=68)\end{array}$ & $\begin{array}{l}\text { Combination group } \\
(\mathbf{n}=\mathbf{2 5 6})\end{array}$ & $P$-value & $\begin{array}{l}\text { Monotherapy } \\
\text { group }(n=22)\end{array}$ & $\begin{array}{l}\text { Combination } \\
\text { group }(n=187)\end{array}$ & $P$-value \\
\hline \multicolumn{10}{|c|}{ DAS28 core parameter } \\
\hline DAS28 & $3.13(1.21)$ & $3.19(1.28)$ & 0.677 & $2.65(0.98)$ & $2.70(1.07)$ & 0.842 & $2.36(0.96)$ & $2.37(0.88)$ & 0.947 \\
\hline TJC28 & $5.47(6.32)$ & $5.85(6.53)$ & 0.405 & $4.32(4.43)$ & $4.12(5.02)$ & 0.830 & $4.22(4.89)$ & $2.89(2.69)$ & 0.668 \\
\hline SJC28 & $3.56(4.23)$ & $5.18(5.64)$ & $0.031^{*}$ & $3.17(2.79)$ & $3.88(4.45)$ & 0.754 & $3.40(4.79)$ & $2.83(2.87)$ & 0.942 \\
\hline $\mathrm{CRP}, \mathrm{mg} / \mathrm{L}$ & $7.70(12.60)$ & $8.46(14.19)$ & 0.678 & $4.05(7.17)$ & $6.62(11.10)$ & $0.021^{*}$ & $3.21(7.51)$ & $4.45(9.25)$ & 0.286 \\
\hline \multicolumn{10}{|c|}{ Secondary endpoint } \\
\hline PtGA & $42.32(17.25)$ & $44.84(17.17)$ & 0.265 & $40.47(15.36)$ & $41.23(16.93)$ & 0.746 & $32.55(19.36)$ & $35.10(17.03)$ & 0.515 \\
\hline HAQ & $1.15(2.39)$ & $1.06(2.16)$ & 0.520 & $0.88(2.06)$ & $0.80(2.41)$ & 0.736 & $0.59(1.26)$ & $0.33(0.95)$ & 0.112 \\
\hline MSD, min & $10.28(21.92)$ & $10.50(22.16)$ & 0.298 & $7.48(19.02)$ & $7.18(20.15)$ & 0.148 & $5.59(18.27)$ & $3.59(11.40)$ & 0.753 \\
\hline ESR, mm/h & $20.06(35.41)$ & $19.19(22.88)$ & 0.192 & $17.35(18.95)$ & $18.59(19.93)$ & 0.831 & $14.29(15.18)$ & $13.66(17.43)$ & 0.637 \\
\hline
\end{tabular}

Table 2. Clinical outcomes at baseline, month 1 and month 3. Values are means (SD). DAS28 28-joint disease activity score calculated with C-reactive protein, TJC28 tender joint count of 28 joints, SJC28 swollen joint count of 28 joints, PtGA patient global assessment, CRP C-reactive protein, HAQ health assessment questionnaire, $M S D$ morning stiffness duration, ESR erythrocyte sedimentation rate. ${ }^{\star} P<0.05$.

A

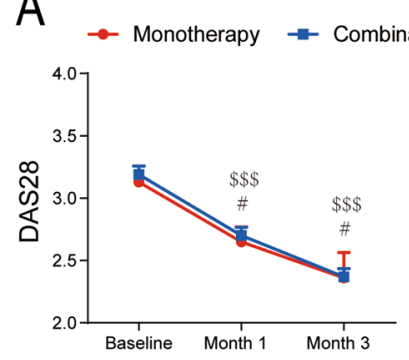

E

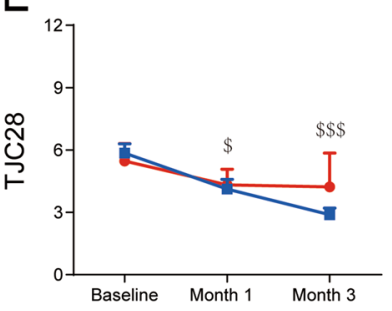

B

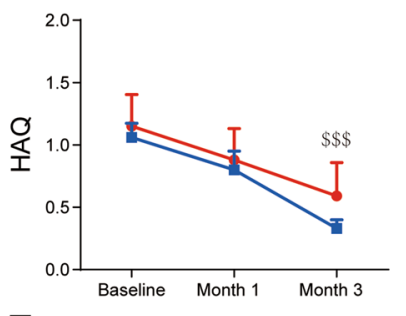

F

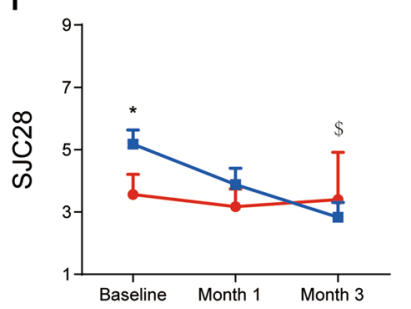

C

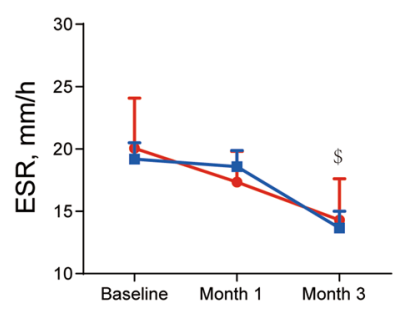

G

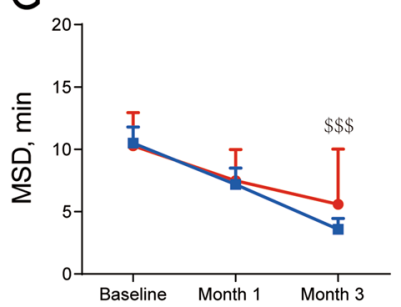

D

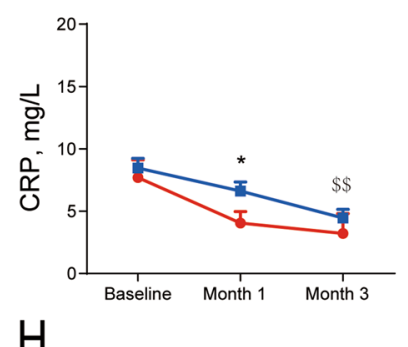

H

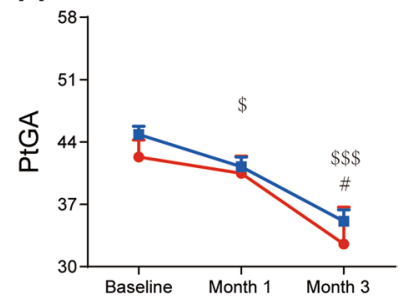

Figure 1. Primary and secondary endpoint results for the monotherapy and combination groups. (A) DAS28, (B) HAQ, (C) ESR, (D) CRP, (E) TJC28, (F) SJC28, (G) MSD, (H) PtGA. DAS28 28-joint disease activity score calculated with $\mathrm{C}$-reactive protein, $H A Q$ health assessment questionnaire, CRP C-reactive protein, ESR erythrocyte sedimentation rate, TJC28 tender joint count of 28 joints, SJC28 swollen joint count of 28 joints, $M S D$ morning stiffness duration, PtGA patient global assessment. Data are shown as means \pm SEM. ${ }^{\star}$ Indicate significant differences between different groups at the same time point $(P<0.05)$. "Significance as compared with baseline in the monotherapy group $(P<0.05)$. \$Significance as compared with baseline in the combination group $\left({ }^{\$} P<0.05 ;{ }^{\$} P<0.01 ;{ }^{\$ \$} P<0.001\right)$.

similar results with $23.44 \%, 21.88 \%$ and $54.69 \%$ having a good response, moderate response and no response, respectively. At month 3, the proportion of good response in the monotherapy group (23.44\%) was lower than that in the combination group (26.75\%). Still, the composition ratios of no response, moderate response and good response were not significantly different between the two groups $(P>0.05)$. Taken together, these results confirmed that there was no significant difference in efficacy between the monotherapy group and the combination therapy group at month 1 and month 3 .

Safety. The hematological examination results before and after administration of monotherapy and combination therapy are shown in Table 3. Regardless of whether patients were in the monotherapy group or the combination group, the four blood routine indicators (hemoglobin (HGB), red blood cell (RBC), mean corpuscular volume (MCV), and white blood cell (WBC) showed similar results before and after the treatment. There were also no significant differences in liver function (albumin (ALB), aspartate transaminase (AST) and alanine transaminase (ALT)) or kidney function indicators (glomerular filtration rate (GFR) and serum creatinine 


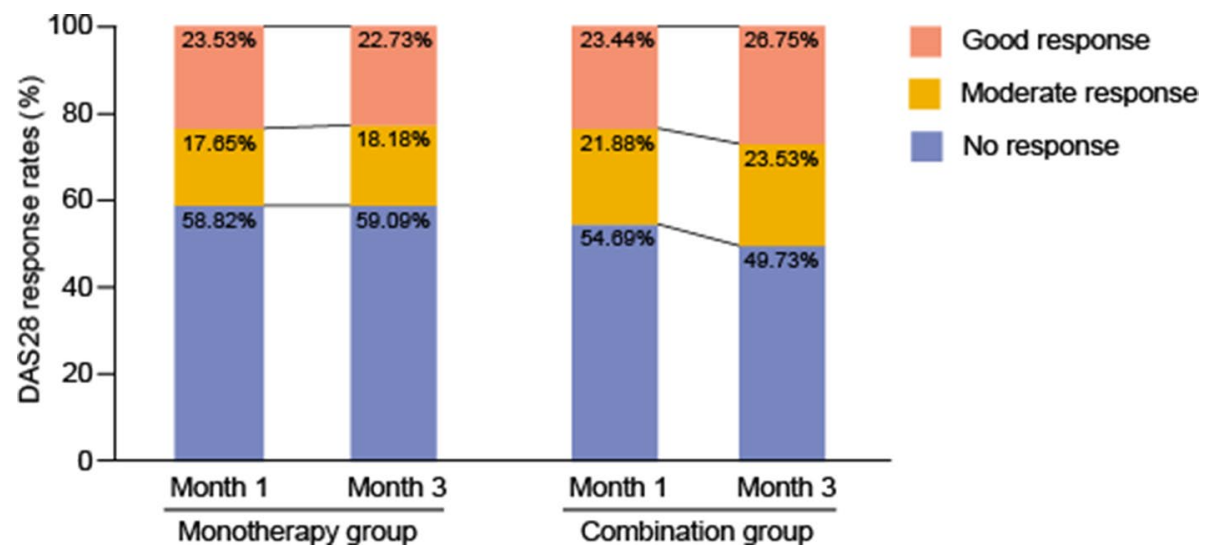

Figure 2. DAS28 response rates in the monotherapy and combination groups.

\begin{tabular}{|c|c|c|c|c|c|c|}
\hline \multirow[b]{2}{*}{ Characteristic } & \multicolumn{3}{|l|}{ Monotherapy group } & \multicolumn{3}{|c|}{ Combination group } \\
\hline & Premedication $(n=43)$ & $\begin{array}{l}\text { Post-medication } \\
(\mathrm{n}=18)\end{array}$ & $\Delta$ & $\begin{array}{l}\text { Premedication } \\
(\mathrm{n}=151)\end{array}$ & $\begin{array}{l}\text { Post-medication } \\
(\mathrm{n}=106)\end{array}$ & $\Delta$ \\
\hline \multicolumn{7}{|l|}{ Blood routine } \\
\hline HGB, g/L & $128.83(15.58)$ & $131.92(13.07)$ & 3.09 & $123.91(15.96)$ & $123.83(19.70)$ & -0.08 \\
\hline $\mathrm{RBC}, 10^{12} / \mathrm{L}$ & $4.24(0.39)$ & $4.33(0.38)$ & 0.09 & $4.22(0.61)$ & $4.26(0.58)$ & 0.04 \\
\hline $\mathrm{MCV}, \mathrm{fL}$ & $92.71(4.68)$ & $94.26(6.83)$ & 1.55 & $91.45(7.25)$ & $91.66(8.21)$ & 0.21 \\
\hline $\mathrm{WBC}, 10^{9} / \mathrm{L}$ & $6.07(1.72)$ & $5.63(1.32)$ & -0.44 & $6.21(2.06)$ & $5.46(1.85)$ & -0.75 \\
\hline \multicolumn{7}{|l|}{ Liver results } \\
\hline $\mathrm{ALB}, \mathrm{g} / \mathrm{L}$ & $43.92(5.10)$ & $45.04(3.86)$ & 1.12 & $43.15(4.07)$ & $43.72(4.23)$ & 0.57 \\
\hline AST, U/L & $23.10(9.87)$ & $23.47(7.73)$ & 0.37 & $24.17(10.80)$ & $27.31(13.64)$ & 3.14 \\
\hline ALT, U/L & $19.97(7.34)$ & $27.89(17.95)$ & 7.92 & $22.83(12.21)$ & $26.85(14.99)$ & 4.02 \\
\hline \multicolumn{7}{|l|}{ Kidney results } \\
\hline $\mathrm{GFR}, \mathrm{mL} / \mathrm{min}$ & $84.70(23.77)$ & $94.83(13.53)$ & 10.13 & $89.60(28.84)$ & $86.85(24.14)$ & -2.75 \\
\hline $\mathrm{Scr}, \mu \mathrm{mol} / \mathrm{L}$ & $61.98(11.86)$ & $52.09(10.87)$ & -9.89 & $53.11(10.89)$ & $58.21(19.39)$ & 5.10 \\
\hline
\end{tabular}

Table 3. Changes of hematological examination before and after medication. Values are means (SD). HGB hemoglobin, $R B C$ red blood cell, $M C V$ mean corpuscular volume, $W B C$ white blood cell, $A L B$ albumin, $A S T$ aspartate transaminase, $A L T$ alanine transaminase, GFR glomerular filtration rate, $S c r$ serum creatinine, $\Delta$ the change before and after medication.

(Scr)). Multiple hematological examination results before and after treatment revealed that the safety was similar in the monotherapy and combination groups.

Subgroup analysis. The combination group included three treatment regimens, and we compared the efficacy of the four medication regimens in the treatment of RA (Supplementary Table S1, Supplementary Fig. S1). At baseline, the DAS28 were 3.13 \pm 1.21 (LEF), $3.37 \pm 1.29$ (LEF + MTX), 2.89 \pm 1.21 (LEF + HCQ) and 3.22 \pm 1.27 $(\mathrm{LEF}+\mathrm{MTX}+\mathrm{HCQ})$, respectively, with no significant difference $(P>0.05)$. DAS28, HAQ, ESR, CRP, TJC28, SJC28 and PtGA in the four groups had similar results at month 1 and month 3 (all $P>0.05$ ), except for MSD at baseline. Thus, there was no significant difference in efficacy of the four regimens at month 1 and month 3 .

We further analyzed the efficacy of LEF in patients who received $<20 \mathrm{mg} /$ day (low dose) or $\geq 20 \mathrm{mg} /$ day (high dose) of LEF in the monotherapy group and in the combination group (Supplementary Fig. S2). DAS28, HAQ, ESR, CRP, TJC28, MSD and PtGA were remarkably similar among the four groups at baseline, month 1 and month 3. Except that, SJC28 was significantly lower in the high dose monotherapy group at baseline. In summary, there were no significant differences in the primary and secondary endpoints among the four groups at baseline, month 1 and month $3(P>0.05)$.

\section{Discussion}

In the retrospective cohort study, we mainly compared the efficacy between RA patients with LEF monotherapy and LEF combination therapy with csDMARDs. Our study reported that there were no significant differences in the primary endpoint DAS28 and multiple secondary endpoints between the monotherapy group and the combination group after 3 months of treatment. Both groups also have similar safety. In the subgroup analysis of treatment regimen, clinical outcomes in patients treated with LEF, LEF + MTX, LEF + HCQ, and LEF + MTX + HCQ 
was similar. When the dose of LEF was in the high dose or low dose levels, the dose of LEF had no significant effect on the efficacy of the treatment regimen, either alone or combined with other csDMARDs.

LEF, typical csDMARDs, effectively inhibits the activated immune response and has good efficacy and safety in the treatment of $\mathrm{RA}^{9,32}$. Compared with placebo, LEF significantly improved clinical outcomes in RA patients at month 1 and month $3^{11}$. SSZ was similar to LEF in terms of CRP, MSD and HAQ after 6 months ${ }^{11,12}$. In our study, DAS28 and PtGA were significantly reduced in the monotherapy group (LEF) at month 3 compared to baseline, which suggested that LEF was an effective drug for RA treatment. In the clinical therapy of RA, the recommended dose for $\mathrm{LEF}$ is $20 \mathrm{mg} / \mathrm{day}^{13}$. However, Mladenovic et al. came to a conclusion that there was no significant difference in efficacy between $10 \mathrm{mg} /$ day and $20 \mathrm{mg} /$ day LEF after 4 weeks treatment. When the daily dose of LEF was $5 \mathrm{mg}$, the effect was similar to placebo ${ }^{14}$. Our results showed that there was no significant difference in efficacy between low dose LEF $(<20 \mathrm{mg} /$ day $)$ and high dose LEF ( $\geq 20 \mathrm{mg} /$ day) after 1 month and 3 months therapy. The low dose was mainly $10 \mathrm{mg}$ /day, while the high dose was mainly $20 \mathrm{mg} /$ day. LEF dose was positively correlated with liver enzyme elevation and adverse events ${ }^{14,33}$, so low dose LEF was worth considering within the same efficacy.

In treatment strategies for RA, drugs are often used in combination to prevent disease progression ${ }^{8}$. However, a study in RA patients with step-up therapy strategy demonstrated that LEF monotherapy and combination therapy has been similar efficacy, that was, there was no significant difference in DAS28 response rate and American College of Rheumatology (ACR) 20 score between LEF + SSZ and SSZ + placebo after 6 months of treatment ${ }^{31}$. Our study was a parallel strategy in which the combination group received one or more csDMARDs simultaneously. There was no significant difference in efficacy of the combination group at month 1 and month 3 compared to the LEF monotherapy group. Both studies with different study designs substantiated that LEF monotherapy was not inferior to csDMARDs combined therapy. However, LEF combined with drugs that have different mechanisms of action may improve therapy efficacy, for instance integrative LEF and rituximab is significantly more effective than rituximab alone ${ }^{34}$. Therefore, the combination of LEF with drugs with different modes of action seems to increase the benefits more than with csDMARDs.

As a chronic disease, RA is generally with long treatment period and complicated medication regimen. It was inevitable in our study that patients took other drugs before the assessment. However, the disease activity of the two therapy groups at baseline was at the same level, and there was no significant influence on the efficacy evaluation of LEF in this study. Of note, we excluded patients who took GCs to avoid the influence of GCs on the evaluation of efficacy. Although some studies have found that GCs included in treatment do not have a significant impact on the efficacy of MTX + GCs or MTX + GCs + other csDMARDs (LEF or SSZ or SSZ + HCQ) ${ }^{29,30}$, other studies included GCs treatment regimen have different opinions, which have shown that combination therapy was better than monotherapy ${ }^{25,35}$. Different conclusions might be partly caused by differences in study designs ${ }^{36}$, treatment regimens, observation time and evaluation indicators. Therefore, our study reduced confounding factors to some extent. Besides, we counted several indicators, such as DAS28, HAQ, ESR, CRP, TJC28, SJC28 and DAS28 response rate in our study. This facilitates comparisons between studies.

The combination of multiple drugs usually increases drug toxicity ${ }^{20}$, but our study found that there was no significant change in blood routine, liver and kidney function in the monotherapy group or the combination group before and after medication. Therefore, the safety of the two groups was similar. Analogous conclusion was reached in the study of Kremer et al. where the incidence of adverse events was similar between the two groups (LEF+MTX and MTX+ placebo) $)^{22}$.

Treatment-driven data inevitably had some potential limitations. First, some patients were lost to follow-up in this retrospective study. At month 3, there were only 22 patients in the monotherapy group, which might result in our conclusion less representativeness and universality. Second, a total of 3 months from baseline to the end of observation was relatively short and evaluation indicators was relatively less. To address these limitations, we should collect complete data from multiple hospitals to increase the sample size, increase follow-up time to help us better understand the dynamic changes of the condition and add other evaluation indicators to more objectively evaluate the efficacy of the drug, such as the simplified disease activity index and clinical disease activity index. Third, the combination group contained three treatment regimens, which resulted in the sample imbalance between the combination group and the monotherapy group, and might have a certain impact on the statistical power. However, in the subgroup analysis of treatment regimens, the combination group was divided into three subgroups, with a relatively balanced number of patients in each group, which reduced the impact of sample inequality on the results. And, the result of subgroup analysis was consistent with the main conclusion of LEF monotherapy versus combination therapy comparison, that was, the efficacy of LEF monotherapy was not inferior to LEF combination therapy.

In conclusion, the efficacy of LEF monotherapy and LEF combined with csDMARDs was similar. However, LEF monotherapy was a more economical treatment regimen than combination therapy. At the same time, the low dose of LEF (10 mg/day) was also worth considering.

\section{Methods}

Patients. Data on patients with RA were collected at Mianyang Central Hospital in southwest China from January 2015 to June 2019. The study was based on clinical data and independently reviewed and approved by the local ethics committee (Ethics Committee of Dazhou Central Hospital, approval number: IRB0000000319003). As this study was not risky for the subjects, the Ethics Committee waived the need for patients to sign informed consent. All methods were carried out in accordance with relevant guidelines and regulations.

Patients over 18 years of age and diagnosed with RA based on the ACR 1987 revised criteria were retrospectively enrolled in the study ${ }^{37}$. Exclusion criteria mainly included the following: (1) patients without medication information; (2) Patients did not receive LEF; (3) patients had taken GCs; (4) the time of medication did not 


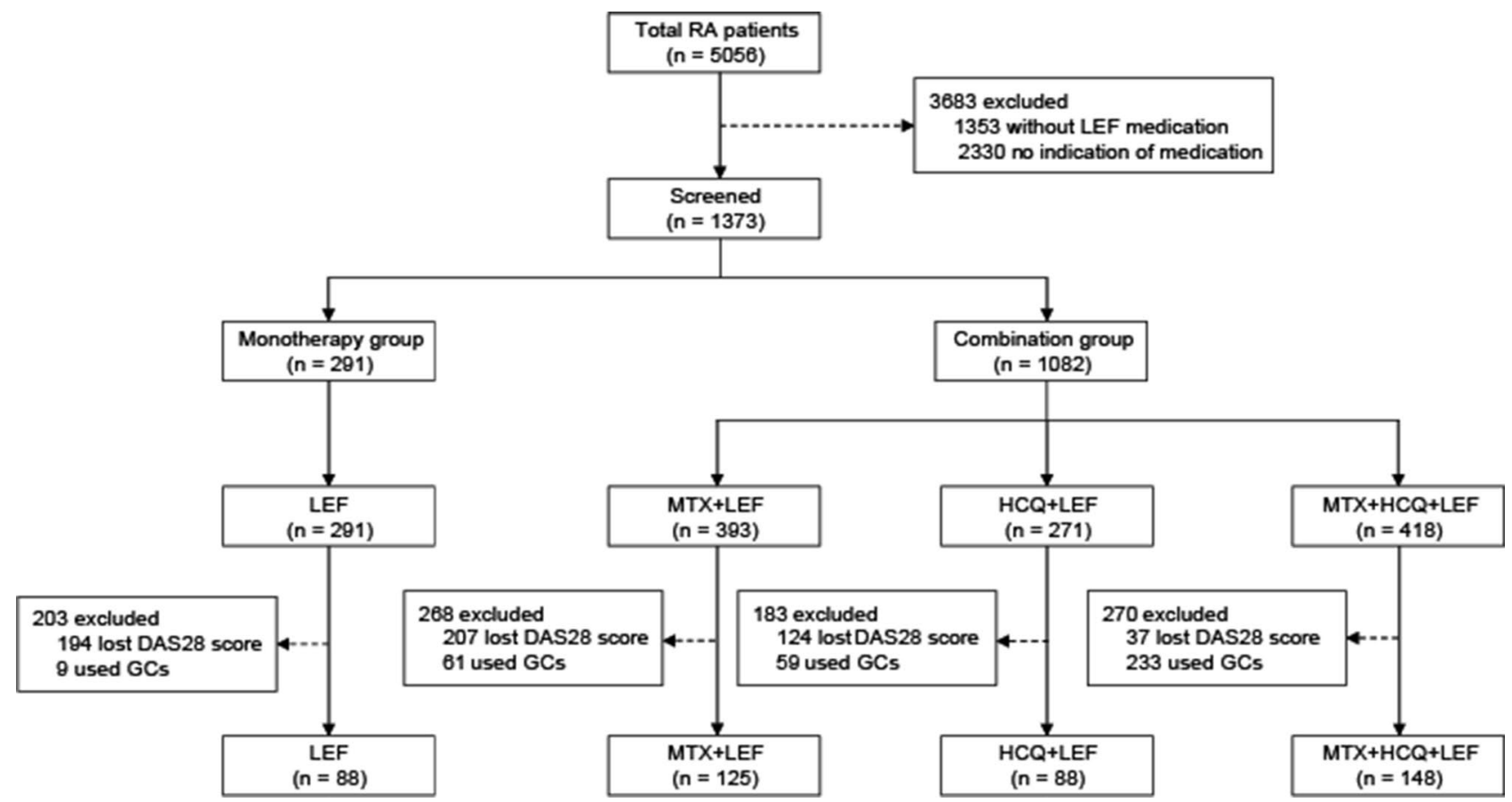

Figure 3. Selection of the study population. $R A$ rheumatoid arthritis, DAS28 28-joint disease activity score calculated with C-reactive protein, $L E F$ leflunomide, MTX methotrexate, HCQ hydroxychloroquine, GCs glucocorticoids.

match the assessment time of the primary endpoint; (5) missing DAS28 score calculated with CRP. Patients who had complications such as diabetes, hypertension, and osteoporosis were not excluded. Patients taking nonsteroidal anti-inflammatory drugs such as ibuprofen, meloxicam or diclofenac were not excluded. The detailed exclusion process is shown in Fig. 3.

Study design. This retrospective study was followed for 3 months after treatment. The primary and secondary endpoints were assessed at baseline, month 1 and month 3, respectively. According to the medication situation of patients, they were mainly divided into two groups, namely monotherapy group and combination group. The monotherapy group received only LEF, and the combination group received two or three csDMARDs (LEF, MTX or HCQ), which must contain LEF. In the study cohort, the dose of MTX administered was $10.44 \pm 2.93 \mathrm{mg} /$ week (median $10 \mathrm{mg} /$ week). The dose of LEF administered was $14.47 \pm 5.33 \mathrm{mg} /$ day (median $10 \mathrm{mg} /$ day). The dose of HCQ administered was $374.58 \pm 80.62 \mathrm{mg} /$ day (median $400 \mathrm{mg} /$ day).

Subgroups. To further evaluate the efficacy between specific treatment regimens, we performed a subgroup analysis of the combination group. There were three drug regimens included in the subgroup. The first therapeutic regimen was LEF combined with MTX; the second therapeutic regimen was LEF combined with HCQ; the third therapeutic regimen was LEF combined with MTX and HCQ.

In addition, a subgroup analysis was performed based on the dose of LEF, low dose group ( $<20 \mathrm{mg} /$ day) and high dose group ( $\geq 20 \mathrm{mg} /$ day). The median doses of LEF was $10 \mathrm{mg} /$ day (5-15 mg/day) in the low dose group and $20 \mathrm{mg} /$ day (20-40 $\mathrm{mg} /$ day) in the high dose group.

Study endpoints. The primary endpoint was DAS28 at month 3. The secondary endpoints were HAQ, ESR, CRP, TJC28, SJC28, MSD, PtGA and DAS28 response rate. We used EULAR response criteria to calculate the DAS28 response rate after treatment ${ }^{38,39}$. Safety was evaluated based on multiple hematological examinations. The hematological examination included HGB, WBC, MCV, WBC, ALB, AST, ALT, GFR and Scr.

Statistical analysis. Statistical analysis was performed using IBM SPSS Statistics 20.0. GraphPad Prism 8 was used for drawing. Overall differences between groups were tested using the Student's $t$ test or two-way analysis of variance (ANOVA) with Tukey's multiple comparisons test depending on distribution of the variables. Non-normal distribution and continuous variables were tested using the Mann-Whitney $U$ test. Categorical variables were tested with Chi-square test. A two-sided $P$-value $<0.05$ was considered statistically significant. 


\section{References}

1. Ferucci, E. D., Templin, D. W. \& Lanier, A. P. Rheumatoid arthritis in American Indians and Alaska natives: A review of the literature. Semin. Arthrit. Rheum. 34, 662-667. https://doi.org/10.1016/j.semarthrit.2004.08.003 (2005).

2. Strand, V. Recent advances in the treatment of rheumatoid arthritis. Clin. Cornerstone 2, 38-50 (1999).

3. Humphreys, J. H. et al. The incidence of rheumatoid arthritis in the UK: Comparisons using the 2010 ACR/EULAR classification criteria and the 1987 ACR classification criteria. Results from the Norfolk Arthritis register. Ann. Rheum. Dis. 72, 1315-1320. https://doi.org/10.1136/annrheumdis-2012-201960 (2013).

4. Myasoedova, E., Crowson, C. S., Kremers, H. M., Therneau, T. M. \& Gabriel, S. E. Is the incidence of rheumatoid arthritis rising? Results from Olmsted County, Minnesota, 1955-2007. Arthrit. Rheum. 62, 1576-1582. https://doi.org/10.1002/art.27425 (2010).

5. MacGregor, A. J. et al. Characterizing the quantitative genetic contribution to rheumatoid arthritis using data from twins. Arthrit. Rheum. 43, 30-37. https://doi.org/10.1002/1529-0131(200001)43:1<30::AID-ANR5>3.0.CO;2-B (2000).

6. Deane, K. D. et al. Genetic and environmental risk factors for rheumatoid arthritis. Best Pract. Res. Clin. Rheumatol. 31, 3-18. https://doi.org/10.1016/j.berh.2017.08.003 (2017).

7. Scott, D. L., Wolfe, F. \& Huizinga, T. W. Rheumatoid arthritis. Lancet 376, 1094-1108. https://doi.org/10.1016/S0140-6736(10)60826 $-4(2010)$.

8. Smolen, J. S. et al. EULAR recommendations for the management of rheumatoid arthritis with synthetic and biological diseasemodifying antirheumatic drugs: 2019 update. Ann. Rheum. Dis. 79, 685-699. https://doi.org/10.1136/annrheumdis-2019-21665 $5(2020)$.

9. Goldenberg, M. M. Leflunomide, a novel immunomodulator for the treatment of active rheumatoid arthritis. Clin. Ther. 21, 1837-1852. https://doi.org/10.1016/S0149-2918(00)86732-6 (1999).

10. Chong, A. S. et al. In vivo activity of leflunomide: Pharmacokinetic analyses and mechanism of immunosuppression. Transplantation 68, 100-109. https://doi.org/10.1097/00007890-199907150-00020 (1999).

11. Smolen, J. S. et al. Efficacy and safety of leflunomide compared with placebo and sulphasalazine in active rheumatoid arthritis: A double-blind, randomised, multicentre trial. European Leflunomide Study Group. Lancet 353, 259-266. https://doi.org/10.1016/ s0140-6736(98)09403-3 (1999).

12. Scott, D. L. et al. Treatment of active rheumatoid arthritis with leflunomide: Two year follow up of a double blind, placebo controlled trial versus sulfasalazine. Ann. Rheum. Dis. 60, 913-923. https://doi.org/10.1136/ard.60.10.913 (2001).

13. Cutolo, M., Bolosiu, H., Perdriset, G. \& LEADER Study Group. Efficacy and safety of leflunomide in DMARD-naive patients with early rheumatoid arthritis: Comparison of a loading and a fixed-dose regimen. Rheumatology (Oxford) 52, 1132-1140. https:// doi.org/10.1093/rheumatology/kes321 (2013).

14. Mladenovic, V. et al. Safety and effectiveness of leflunomide in the treatment of patients with active rheumatoid arthritis. Results of a randomized, placebo-controlled, phase II study. Arthritis Rheum. 38, 1595-1603. https://doi.org/10.1002/art.1780381111 (1995).

15. Strand, V. et al. Treatment of active rheumatoid arthritis with leflunomide compared with placebo and methotrexate. Leflunomide rheumatoid Arthritis Investigators Group. Arch. Intern. Med. 159, 2542-2550. https://doi.org/10.1001/archinte.159.21.2542 (1999).

16. Emery, P. et al. A comparison of the efficacy and safety of leflunomide and methotrexate for the treatment of rheumatoid arthritis. Rheumatology (Oxford) 39, 655-665. https://doi.org/10.1093/rheumatology/39.6.655 (2000).

17. Kraan, M. C. et al. Modulation of inflammation and metalloproteinase expression in synovial tissue by leflunomide and methotrexate in patients with active rheumatoid arthritis. Findings in a prospective, randomized, double-blind, parallel-design clinical trial in thirty-nine patients at two centers. Arthritis Rheum. 43, 1820-1830. https://doi.org/10.1002/1529-0131(200008)43:8<1820::AIDANR18>3.0.CO;2-D (2000).

18. Chunde, B. et al. Leflunomide, a new disease-modifying drug for treating active rheumatoid arthritis in methotrexate-controlled phase II clinical trial. Chin. Med. J. 116, 1228-1234 (2003).

19. Hu, Y., Tu, S. \& Liu, P. A randomized, controlled, single-blind trial of leflunomide in the treatment of rheumatoid arthritis. J. Tongji Med. Univ. 21, 72-74. https://doi.org/10.1007/BF02888043 (2001).

20. Curtis, J. R. et al. Elevated liver enzyme tests among patients with rheumatoid arthritis or psoriatic arthritis treated with methotrexate and/or leflunomide. Ann. Rheum. Dis. 69, 43-47. https://doi.org/10.1136/ard.2008.101378 (2010).

21. Cannon, G. W. et al. Adverse events with disease modifying antirheumatic drugs (DMARD): A cohort study of leflunomide compared with other DMARD. J. Rheumatol. 31, 1906-1911 (2004).

22. Kremer, J. M. et al. Concomitant leflunomide therapy in patients with active rheumatoid arthritis despite stable doses of methotrexate. A randomized, double-blind, placebo-controlled trial. Ann. Intern. Med. 137, 726-733. https://doi.org/10.7326/0003-4819137-9-200211050-00007 (2002).

23. Strangfeld, A. et al. Comparative effectiveness of tumour necrosis factor alpha inhibitors in combination with either methotrexate or leflunomide. Ann. Rheum. Dis. 68, 1856-1862. https://doi.org/10.1136/ard.2008.098467 (2009).

24. Capell, H. A. et al. Combination therapy with sulfasalazine and methotrexate is more effective than either drug alone in patients with rheumatoid arthritis with a suboptimal response to sulfasalazine: Results from the double-blind placebo-controlled MASCOT study. Ann. Rheum. Dis. 66, 235-241. https://doi.org/10.1136/ard.2006.057133 (2007).

25. Mottonen, T. et al. Comparison of combination therapy with single-drug therapy in early rheumatoid arthritis: A randomised trial. FIN-RACo trial group. Lancet 353, 1568-1573. https://doi.org/10.1016/s0140-6736(98)08513-4 (1999).

26. O'Dell, J. R. et al. Treatment of rheumatoid arthritis with methotrexate alone, sulfasalazine and hydroxychloroquine, or a combination of all three medications. N. Engl. J. Med. 334, 1287-1291. https://doi.org/10.1056/NEJM199605163342002 (1996).

27. O'Dell, J. R. et al. Treatment of rheumatoid arthritis with methotrexate and hydroxychloroquine, methotrexate and sulfasalazine, or a combination of the three medications: Results of a two-year, randomized, double-blind, placebo-controlled trial. Arthritis Rheum. 46, 1164-1170. https://doi.org/10.1002/art.10228 (2002).

28. Goekoop-Ruiterman, Y. P. et al. Comparison of treatment strategies in early rheumatoid arthritis: A randomized trial. Ann. Intern. Med. 146, 406-415. https://doi.org/10.7326/0003-4819-146-6-200703200-00005 (2007)

29. Verschueren, P. et al. Methotrexate in combination with other DMARDs is not superior to methotrexate alone for remission induction with moderate-to-high-dose glucocorticoid bridging in early rheumatoid arthritis after 16 weeks of treatment: The CareRA trial. Ann. Rheum. Dis. 74, 27-34. https://doi.org/10.1136/annrheumdis-2014-205489 (2015).

30. de Jong, P. H. et al. Randomised comparison of initial triple DMARD therapy with methotrexate monotherapy in combination with low-dose glucocorticoid bridging therapy; 1-year data of the tREACH trial. Ann. Rheum. Dis. 73, 1331-1339. https://doi. org/10.1136/annrheumdis-2013-204788 (2014).

31. Dougados, M. et al. When a DMARD fails, should patients switch to sulfasalazine or add sulfasalazine to continuing leflunomide?. Ann. Rheum. Dis. 64, 44-51. https://doi.org/10.1136/ard.2003.016709 (2005).

32. Hamilton, L. C., Vojnovic, I. \& Warner, T. D. A771726, the active metabolite of leflunomide, directly inhibits the activity of cyclo-oxygenase-2 in vitro and in vivo in a substrate-sensitive manner. Br. J. Pharmacol. 127, 1589-1596. https://doi.org/10.1038/ sj.bjp.0702708 (1999).

33. Elshaer, R. E. et al. Leflunomide-induced liver injury in mice: Involvement of TLR4 mediated activation of PI3K/mTOR/NFkappaB pathway. Life Sci. 235, 116824. https://doi.org/10.1016/j.lfs.2019.116824 (2019). 
34. Chatzidionysiou, K. et al. Effectiveness of disease-modifying antirheumatic drug co-therapy with methotrexate and leflunomide in rituximab-treated rheumatoid arthritis patients: Results of a 1-year follow-up study from the CERERRA collaboration. Ann. Rheum. Dis. 71, 374-377. https://doi.org/10.1136/annrheumdis-2011-200003 (2012).

35. Goekoop-Ruiterman, Y. P. et al. Clinical and radiographic outcomes of four different treatment strategies in patients with early rheumatoid arthritis (the BeSt study): A randomized, controlled trial. Arthritis Rheum. 58, S126-135. https://doi.org/10.1002/ art.23364 (2008).

36. Smolen, J. S., Aletaha, D. \& Keystone, E. Superior efficacy of combination therapy for rheumatoid arthritis: Fact or fiction?. Arthritis Rheum. 52, 2975-2983. https://doi.org/10.1002/art.21293 (2005).

37. Arnett, F. C. et al. The American Rheumatism Association 1987 revised criteria for the classification of rheumatoid arthritis. Arthritis Rheum. 31, 315-324. https://doi.org/10.1002/art.1780310302 (1988).

38. Fransen, J. \& van Riel, P. L. The Disease Activity Score and the EULAR response criteria. Rheum. Dis. Clin. N. Am. 35, 745-757. https://doi.org/10.1016/j.rdc.2009.10.001 (2009).

39. van Gestel, A. M., Haagsma, C. J. \& van Riel, P. L. Validation of rheumatoid arthritis improvement criteria that include simplified joint counts. Arthritis Rheum. 41, 1845-1850. https://doi.org/10.1002/1529-0131(199810)41:10<1845::AID-ART17>3.0.CO;2-K (1998).

\section{Acknowledgements}

This work was funded by the National Natural Science Foundation of China (No. 81902861), the Scientific Research Fund of Sichuan Health and Health Committee (No. 18PJ361, No. 19SYJS09) and the Scientific Research Fund of Technology Bureau in Sichuan Province (No. 2018138, No. 2018JY0324, No. 2017SZ0148). And thanks to Yuanpiao Ni, Jianling Dong, Hong Liu and Chunyue Xiao for their help.

\section{Author contributions}

J.Z. contributed to the study design, statistical analysis of data and writing the manuscript. D.D. collected and organized for the data of patients. M.L., S.L., L.T. and J.Z. participated in the collection of data. T.W. and J.W. provided precious comment for the study. F.Z. and J.Y. directed, reviewed and approved the manuscript. All authors participated in the discussion of the manuscript.

\section{Competing interests}

The authors declare no competing interests.

\section{Additional information}

Supplementary information is available for this paper at https://doi.org/10.1038/s41598-020-69309-z.

Correspondence and requests for materials should be addressed to F.Z. or J.Y.

Reprints and permissions information is available at www.nature.com/reprints.

Publisher's note Springer Nature remains neutral with regard to jurisdictional claims in published maps and institutional affiliations.

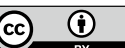

Open Access This article is licensed under a Creative Commons Attribution 4.0 International License, which permits use, sharing, adaptation, distribution and reproduction in any medium or format, as long as you give appropriate credit to the original author(s) and the source, provide a link to the Creative Commons license, and indicate if changes were made. The images or other third party material in this article are included in the article's Creative Commons license, unless indicated otherwise in a credit line to the material. If material is not included in the article's Creative Commons license and your intended use is not permitted by statutory regulation or exceeds the permitted use, you will need to obtain permission directly from the copyright holder. To view a copy of this license, visit http://creativecommons.org/licenses/by/4.0/.

(c) The Author(s) 2020 